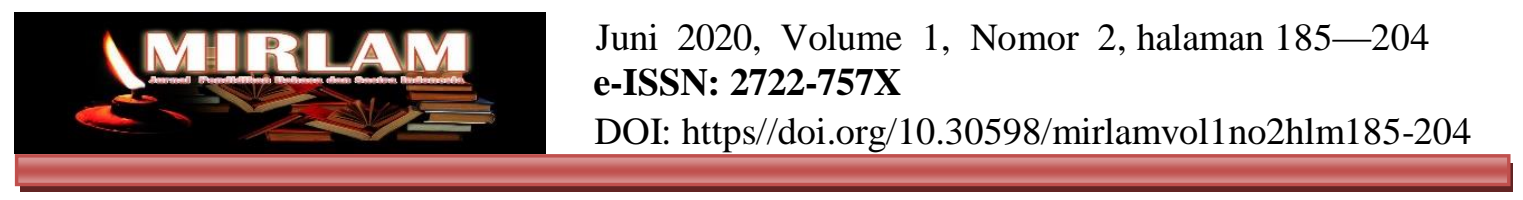

\title{
NILAI BUDAYA DALAM TRADISI DAHISA \\ $B a b A n$ PADA MASYARAKAT DI NEGERI \\ KILKODA KECAMATAN PULAU GOROM KABUPATEN SERAM BAGIAN TIMUR
}

\author{
Saharia Wuarlela \\ Mariana Lewier \\ Heppy Leunard Lelapary
}

\begin{abstract}
ABSTRAK: Sastra merupakan budaya nasional yang mempunyai nilainilai yang perlu dikembangkan dan dimanfaatkan bagi kehidupan masa kini dan masa yang akan datang. Sastra lisan juga telah lama berperan sebagai wahana pemahaman gagasan, pewarisan tata nilai yang tumbuh dan berkembang dalam masyarakat. Sastra lisan merupakan bagian dari nilai suatu kebudayaan yang tumbuh dan berkembang ditengah-tengah arus globalisasi dan dalam masyarakat secara turun-temurun untuk dapat diwariskan sebagai nilai budaya milik bersama. Berbagai bentuk kebudayaan lama yang termasuk dalam sastra lisan, dapat punah jika upaya pelestarian tidak dapat dipertahankan secara turun-temurun oleh anak cucu suatu desa. Secara etimologi kata dahisa berarti 'nikah atau pernikahan', dan babAn berarti 'indah, meriah, terhormat'. Jadi, dahisa merupakan pernikahan yang dilakukan secara indah, meriah dan penuh kehormatan. Rumusan masalah penelitian ini bertujuan untuk mendeskripsikan nilai budaya dalam Tradisi Dahisa BabAn pada masyarakat di Negeri Kilkoda Kecamatan Pulau Gorom Kabupaten Seram Bagian Timur.
\end{abstract}

Kata kunci: sastra lisan, nilai budaya, Tradisi Dahisa babAn 


\title{
CULTURAL VALUES IN DAHISA BabAn CHAPTER OF COMMUNITY TRADITION IN KILKODA KECAMATAN PULAU GOROM STATE SERAM BAGIAN TIMUR DISTRICT
}

\author{
Saharia Wuarlela \\ Mariana Lewier \\ Heppy Leunard Lelapary
}

\begin{abstract}
Literature is a national culture that has values that need to be developed and utilized for life today and in the future. Oral literature also has long served as a vehicle for understanding ideas, inheriting values that grow and develop in society. Oral literature is part of the value of a culture that grows and develops in the midst of globalization and in society for generations to be inherited as a shared cultural value. Various forms of old culture that are included in oral literature can be extinct if cons ervation efforts cannot be maintained for generations by the children of a village. Etymologically the word dahisa 'means marriage or marriage', and babAn means 'beautiful, lively, honorable'. So, dahisa $b a b A n$ is a marriage that is done beautifully, lively and full of honor. The problem statement of this study aims to describe the cultural values in the BabAn Dahisa tradition to the people in Kilkoda Country, Gorom Island District, East Seram Kabupaten.
\end{abstract}

Keywords: oral literature, cultural values, Traditions Dahisa babAn 


\section{A. PENDAHULUAN}

Sastra lisan merupakan salah satu budaya nasional yang mempunyai nilainilai yang perlu dikembangkan dan dimanfaatkan bagi kehidupan masa kini dan masa yang akan datang. Bahasa sastra lisan, termasuk cerita lisan, merupakan budaya nasional dan masih mempunyai nilai-nilai yang patut dikembangkan untuk generasi yang akan datang.

Huck dan kawan-kawan (dalam Nurgiantoro, 2005:26), sastra tidak saja merefleksikan nilai-nilai sosial budaya masyarakat, tetapi mengantar nilai-nilai tersebut kepada masyarakat kini. Hal itu disebabkan sastra pada generasi berikutnya. Sastra juga merupakan karya dan kegiatan seni yang berhubungan dengan ekspresi dan penciptaan. Sastra dapat merangkum, menampung, menyimpan dan kemudian mewariskannya kepada generasi yang kemudian tentang tradisi, pandangan hidup, nilai-nilai dan berbagai hal yang terkait dengan kehidupan sosial, budaya masyarakat bersangkutan.

Sumardjo dan Saini (1994:3), mengatakan bahwa sastra adalah ungkapan pribadi manusia yang berupa pengalaman, pemikiran, perasaan, ide, semangat, dalam suatu kongket yang membangkitkan pesona dengan alat bahasa. Hal ini pun dipertegas oleh (Nyoman Kuartha Ratna, 2005:516), bahwa melalui bahasa sastra menampilkan kualitas estetis sekalipun dokumentasi aspek-aspek bahasa.

Sastra adalah suatu kegiatan kreatif sebuah karya seni (Wellek dan Warren, 1990:3), seni mengabdi kepada keindahan dan keindahan adalah bentuk yang menyenangkan dan bentuk adalah kunci kehidupan sebab tidak ada sesuatu yang 
hidup tanpa bentuk (Pasterna dalam Sumardjo, 1984:18), sastra dihargai karena berguna bagi kehidupan manusia, sastra mengungkapkan berbagai pengalaman manusia agar manusia lain lebih menjadi baik hidupnya. Sastra yang baik jika itu berhasil memberi pengalaman pada manusia agar dapat menjadi suatu pelajaran.

Sastra merupakan salah satu cabang kesenian yang selalu berada dalam peredaan manusia semenjak ribuan tahun lalu. Kehadiran sastra ditengah peradaban manusia tidak dapat ditolak, bahkan kehadirannya tersebut diterima sebagai salah satu realitas sosial budaya (Semi, 1993:1). Disamping itu Semi mengatakan bahwa sastra adalah bagian dari masyarakat yang tak bisa dipisahkan.

Sastra lisan adalah sastra yang disampaikan dari mulut seorang pencerita atau penyair kepada seseorang atau sekelompok pendengar (Atmazaki, 1990:82), dengan demikian, komunikasi antara pencipta dengan penikmat adalah komunikasi langsung. Penikmat sastra lisan dalam suatu kesatuan waktu lebih terbatas dari pada sastra tertulis.

Dahisa BabAn merupakan pernikahan yang dilaksanakan seistimewa atau seindah mungkin dan mempunyai makna yang sangat berharga bagi masyarakat di Negeri Kilkoda. Tidak dapat dipungkiri bahwa, pernikahan adalah momen penting dalam kehidupan setiap manusia. Pada dasarnya definisi pernikahan itu hakikatnya sama dan tidak ada perbedaan di setiap kebudayaan, karena dapat di artikan tujuan dari pernikan adalah menjalin hidup yang baru untuk mencapai suatu kebahagiaan. 
Rumusan masalah yang penulis angkat dalam penelitian ini adalah bagaimanakah nilai budaya dalam tradisi Dahisa BabAn pada masyarakat di Negeri Kilkoda Kecamatan Pulau Gorom, Kabupaten Seram Bagian Timur.

\section{B. METODE PENELITIAN}

Penelitian ini menggunakan model penelitian kualitatif. Penelitian kualitatif adalah penelitian yang bermaksud untuk memahami fenomena tentang apa yang dialami oleh subjek penelitian misalnya perilaku, persepsi, motivasi, dan tindakan secara holistik dan dengan cara deskripsi dalam bentuk tuturan berupa kata-kata dan bahasa, pada suatu konteks. Penelitian kualitatif juga merupakan penellitian yang semua datanya berupa uraian-uraian tanpa angka. Uraian tersebut menjelaskan bagaimana penelitian dilakukan dengan menarik kesimpulan berdasarkan analisis kualitatif.

\section{PEMBAHASAN}

\section{Nilai Semangat dalam Berusaha}

Nilai semangat dalam berusaha adalah nilai yang tumbuh dalam diri seseorang atau kelompok masyarakat dalam berusaha untuk mendapatkan apa yang akan dicapainya. Nilai semangat dalam berusaha tersebut, terdapat dalam tuturan yang pertama untuk meminang/masuk minta. 


$$
\begin{aligned}
& \text { BD : "Tok...Tok...Tok.. Wawina doran } \\
& \text { wawina" } \\
& \text { TG : Tok...Tok...Tok... Perempuan } \\
& \text { minta perempuan (dituturkan } \\
& \text { berulang-ulang) } \\
& \text { TB : Tok...Tok...Tok... Perempuan } \\
& \text { meminta perempuan (dituturkan } \\
& \text { berulang-ulang) }
\end{aligned}
$$

Dari tuturan pertama pada tuturan ini menunjukan bahwa calon mempelai laki-laki dan keluarganya penuh dengan semangat dalam berusaha untuk mengungkapkan keinginan hati mereka kepada calon mempelai perempuan dan keluarganya, tuturan ini menceritakan bahwa calon mempelai laki-laki dan keluarganya memintah seseorang perempuan, dan terus meminta. Calon mempelai laki-laki berharap supaya calon mempelai perempuan yang diminta dapat menerima permintaanya untuk hidup bersama dengannya apapun keadaaannya, baik suka maupun duka, keduanya dapat menjalani secara bersama, saling melengkapi antara yang satu dengan yang lain, serta dapat menutupi kekurangan yang satu dengan yang lain. Sikap semangat dalam berusaha yang ditunjukan oleh calon mempelai laki-laki dan keluarganya, bukan saja pada saat ada proses peminangan tetapi sikap semangat dalam berusaha itu akan terus menjadi bagian dari hidup calon mempelai laki-laki kelak ketika mereka telah ada dalam sutu keluarga, calon mempelai pria akan menjadi seorang pemimpin rumah tangga yang selalu berusaha dalam memenuhi seluruh kebutuhan hidup yang diperlukan. 


\section{Nilai Pantang Menyerah}

Selain nilai semangat dalam berusaha pada manusia sebagai individu, terdapat juga nilai pantang menyerah. Nilai pantang menyerah adalah sikap seseorang atau masyarakat yang tidak mudah menyerah ketika ada hambatan atau rintangan dalam mendapatkan apa yang diinginkan. Nilai pantang menyerah dapat dilihat dari pada tuturan di acara meminang/masuk minta.

$$
\begin{aligned}
& \text { BD : Tok...Tok...Tok... Matahari ma } \\
& \text { nadudu } \\
& \text { TG : Tok...Tok...Matahari mau turun } \\
& \text { TB : Tok...Tok...Matahari akan turun. }
\end{aligned}
$$

Dalam tuturan yang mengisi kalimat matahari akan turun, yang mengandung arti bahwa hari telah sore, menunjukan bahwa calon mempelai laki-laki dan keluarganya meminta seorang perempuan dengan menunjukan sikap pantang menyerah, walaupun matahari sudah turun namun hal tersebut tidak mempengaruhi dan menghentikan niat mereka untuk memintah seorang perempuan yang dicintai calon mempelai laki-laki tersebut. Bagi calon mempelai laki-laki dan keluarganya waktu itu tidak dilalui bersama orang yang disayangi dan dicintai, tetapi jika waktu yang singkat dan dapat dilalui dengan orang yang disayangi maka waktu itu akan memiliki arti tersendiri dalam hidupnya.

Pada kalimat matahari akan turun juga menunjukan bahwa calon mempelai laki-laki dan keluarganya tidak akan menghentikan keinginan mereka, tetapi bagi 
mereka hal tersebut akan membuat mereka terus bersemangat dan ada dalam mengutamakan niat dan tujuan untuk meminang perempuan yang dicintai oleh calon mempelai laki-laki, sehingga ketika keluarga dari calon mempelai perempuan melihat hal tersebut, mereka akan membuka hati dan pintu rumahnya serta dapat menerimah peminangan dari pihak laki-laki dan keluarga.

\section{Nilai Rendah Hati}

Nilai rendah hari adalah sikap seseorang yang memiliki makna luar biasa, yaitu mampu mengakui kekurangan dan mampu mengakui bahwa ia memerlukan orang lain, juga siap melakukan apapun untuk orang lain. Nilai renda hati dapat dilihat pada tuturan

$$
\begin{array}{ll}
\text { BD : } & \begin{array}{l}
\text { Ami arendakan diri ra sama tu } \\
\text { seekor bibi ye mancia woun }
\end{array} \\
\text { TG : } & \begin{array}{l}
\text { Kami rendah diri sama seekor } \\
\text { kambing untuk orang lain }
\end{array} \\
\text { TB : } & \begin{array}{l}
\text { Kami merendah diri sama } \\
\text { sepertiseekor kambing untuk orang } \\
\text { lain }
\end{array}
\end{array}
$$

Dapat dilihat dari tuturan ini pihak laki-laki (warana) mengumpamakan dirinya seperti seekor kambing. Kambing pada masyarakat Kilkoda bagaikan binatang yang paling rendah dan selalu mengikuti keinginan orang lain tanpa mengingat dirinya sendiri. Kata seekor kambing yang dipakai menunjukan bahwa pihak mempelai laki-laki dan keluarga siap melakukan apa saja ketika diminta oleh orang lain (dalam hal ini pihak mempelai perempuan dan keluarganya) asalkan calon 
mempelai perempuan dan keluarganya bersedia menerima peminangan dari mempelai laki-laki. Dalam proses mengumpamakan diri bagaikan seekor kambing, calon mempelai laki-laki dan keluarganya berharap bahwa calon mempelai perempuan dan keluarganya akan melihat pengorbanan yang telah pihak laki-laki dan keluarganya lakukan agar pihak perempuan akan menerima pengorbanan itu tetapi bukan dengan terpaksa atau kasihan melainkan bahwa calon memepelai perempuan dan keluarganya menyadari bahwa calon mempelai laki-laki dan keluarganya melakukan semua itu berdasarkan rasa sayang dan tulus dalam melakukannya.

\section{Nilai Kejujuran}

Nilai kejujuran adalah nilai kebaikan yang sifatnya positif, yaitu lurus hati, tidak berbohong, tulus, dan iklas. Terkait dengan nilai kejujuran yang dapat dilahat dari tuturan, khusunya pada proses acara meminang atau masuk minta.

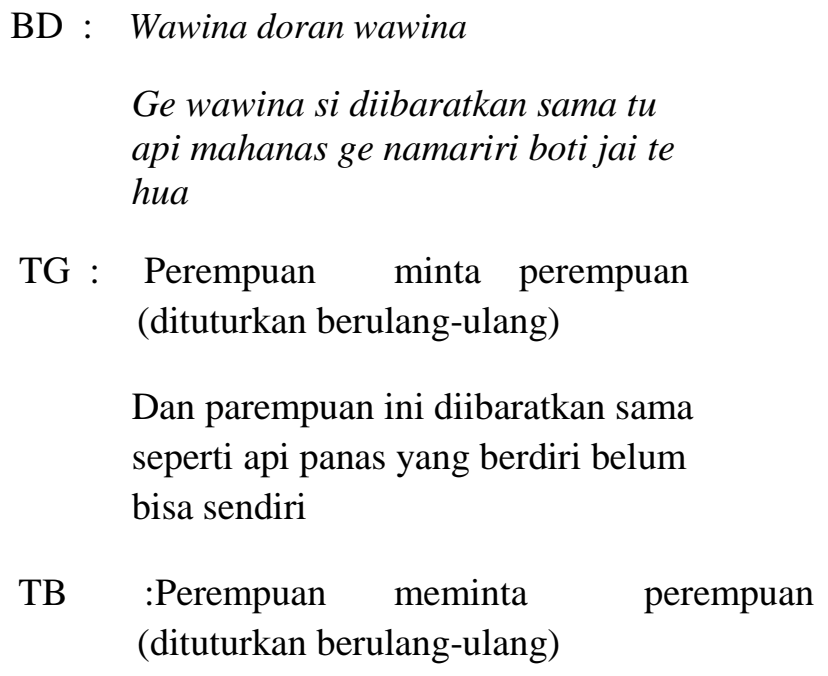


Dan parempuan ini diibaratkan

seperti api panas yang belum bisa

berdiri sendiri.

Masyarakat Negeri Kilkoda mengaku bahwa ketika seorang laki-laki bertemu dengan seprang perempuan yang dicintainya maka keduanya akan hidup selamanya. Oleh karena itu, pihak laki-laki mengetakui kebenarannya dengan jujur serta mengakui diri apa adanya, bahwa calon mempelai laki-laki bagaikan seorang individu yang tidak dapat menjalani hidupnya seorang diri tanpa seorang mempelai perempuan untuk mendampingi hidupnya. Bagi calon mempelai laki-laki, calon memepelai perempuan bagaikan api yang dapat menghangatkan hidup mempelai laki-laki, ketika mereka hidup bersama serta dengan cahaya matahari yang terpancar dari perampian itu maka akan menerangi kehidupan keduanya dikemudian hari.

\section{Nilai Saling Mempercayai}

Nilai saling percaya adalah harapan yang tumbuh dalam masyarakat yang ditunjukan oleh adanya perilaku jujur, teratur, kerja berdasarkan norma-norma yang dianut bersama-sama anggota masyarakat. Nilai saling mempercayai terdapat dalam tuturan untuk memberi pesan.

\footnotetext{
BD : Buah mas tu ni daun, ge harus ta berikan ke pihak wararaniorang tua si

TG : Buah mas dan daun diberikan ke pihak pria dan orang tuanya.
} 


\section{TB : Buah mas dan daun harus diberikan kepada orang tua pihak pria.}

Istilah buah mas dan daun mas menunjukan bahwa sesuatu yang sangat berharga sehingga pada saat pihak perempuan menyerahkan anak mereka (mempelai perempuan) kepada calon mempelai laki-laki dan keluarganya, mereka menunjukan bahwa mereka mempercayai anak mereka untuk dijaga, dan disayangi oleh pihak mempelai laki-laki, sehingga mereka mengumpamakan anak mereka (mempelai perempuan) bagaikan buah mas, yang diambil dan buah mas itu harus dijaga dengan baik.

\section{Nilai Saling Menghormati}

Nilai saling menghormati adalah suatu sikap saling menghargai satu sama lain saat kita dimasyarakat, kita harus mengayomi yang tua lindungi yang muda. Dalam tuturan yang diucapkan pada proses upacara adat khususnya tuturan untuk mengambil mempelai perempuan dari dalam rumah.

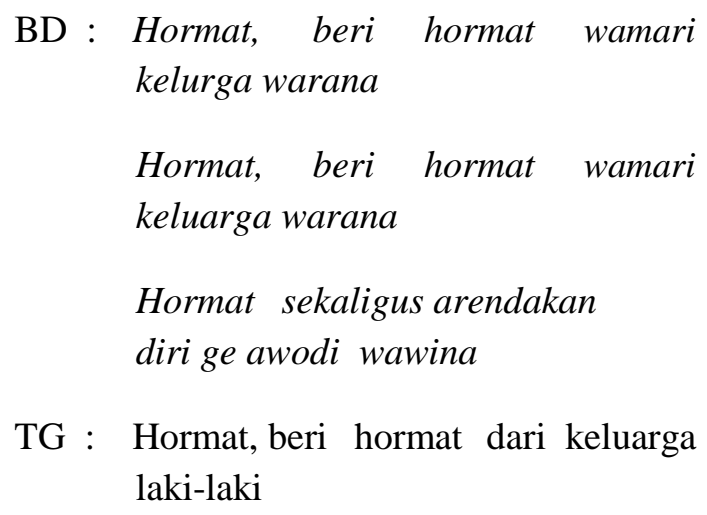


memberi hormat

Kami dari keluarga laki-laki

memberi hormat

Kami memberi hormat sekaligus

merendahkan diri untuk mengambil

perempuan.

Dalam tuturan ini pihak mempelai laki-laki dan keluarganya, mengungkapkan rasa hormat mereka kepada mempelai perempuan dan keluarganya, serta mereka merendahkan diri untuk mengambil anak perempuan (mempelai perempuan), karena bagi mereka dengan saling memberi hormat, maka mereka akan mempunyai hubungan keluarga yang baik serta menjaga perasaan antara keluarga yang satu dengan keluarga yang lain.

\section{Nilai Etika}

Nilai etika adalah suatu norma atau aturan yang dipakai sebagai pedoman dalam berperilaku manusia terkait ditata baik dan buruknya. Dari ketiga tuturan yang diucapkan, baik dari pihak mempelai laki-laki, maupun dari pihak mempelai perempuan, terdapat nilai etika didalamnya, dapat dilihat dari tuturan meminang atau masuk minta.

$$
\begin{aligned}
& \text { BD : Tok...Tok...Tok.. Wawina doran } \\
& \text { wawina } \\
& \text { Tok...Tok...Tok... Wawina doran } \\
& \text { wawina } \\
& \text { Ge wawina diibaratkan sama tu api } \\
& \text { mahanas ge namariri boti jai tei hua }
\end{aligned}
$$


Nilai Budaya Dalam Tradisi Dahisa BabAn Pada Masyarakat Di Negeri Kilkoda Kecamatan Pulau Gorom Kabupaten Seram Bagian Timur

Tok...Tok...Tok... Matahari ma nadudu

Ami arendakan diri ra sama tu seekor bibi ge mancia woun

TG : Tok...Tok..Tok... Perempuan minta perempuan (dituturkan berulangulang)

Dan perempuan ini diibaratkan sama seperti api panas yang berdiri belum bisa sendiri

Tok...Tok...Matahari akan turun

Kami rendah diri sama seperti seekor kambing untuk orang lain.

TB : Tok...Tok..Tok... Perempuan meminta perempuan (dituturkan berulang-ulang) 
Dan perempuan diibaratkan sama seperti api panas yang belum bisa berdiri sendiri.

Tok...Tok...Matahari akan turun

Kami merendahkan diri seperti seekor kambing untuk orang lain.

Dapat dilihat dari tuturan untuk mengambil mempelai perempuan.

$$
\begin{aligned}
& \text { BD : Hormat, beri hormat wamari } \\
& \text { keluarga warana } \\
& \text { Hormat sekaligus arenda kan } \\
& \text { mami diri gepani awodi wawina } \\
& \text { sasaat ire, wawina ire mami ana ge } \\
& \text { ma awa wodi bo mami ruma ra } \\
& \text { TG : Hormat, beri hormat dari keluarga } \\
& \text { laki-laki } \\
& \text { Hormat sekaligus rendahkan kami } \\
& \text { diri untuk mengambil perempuan } \\
& \text { Hari ini perempuan ini kami anak } \\
& \text { dan mau di bawa ke rumah. } \\
& \text { TB : Hormat, beri hormat dari keluarga } \\
& \text { laki-laki }
\end{aligned}
$$

Dapat dilihat pula dalam tuturan untuk memberi pesan.

$$
\begin{aligned}
& \text { BD : Buah mas tu ni daun, ge harus ta } \\
& \text { berikan ke pihak warara ni orang } \\
& \text { tua si }
\end{aligned}
$$




$$
\begin{aligned}
\text { TG : } & \begin{array}{l}
\text { Buah mas dan daun harus } \\
\text { diberikan ke pihak pria dan orang }
\end{array} \\
& \text { tua. } \\
\text { TB : } & \begin{array}{l}
\text { Daun dan buah emas harus } \\
\text { diberikan kepada pihak orang tua } \\
\text { pria. }
\end{array}
\end{aligned}
$$

Dari ketiga tuturan ini terdapat nilai etika di dalamnya, karena nilai etika yang digambarkan dengan maksud bahwa, sebagai dua keluarga, yang nantinya akan menjadi satu, seharusnya saling menjaga perasaan keluarga yang satu dengan yang lain, serta menyatakan kerendahan hati kepada pihak lain agar tidak terjadi kesenjangan dalam proses kehidupan yang sementara dijalani.

\section{Nilai Sosial}

Nilai sosial adalah nilai yang dianut oleh suatu masyarakat, dan merupakan sesuatu yang dianggap sangat berharga, baik dan benar dalam keberlangsungan kehidupan masyarakat oleh suatu lingkungan masyarakat.

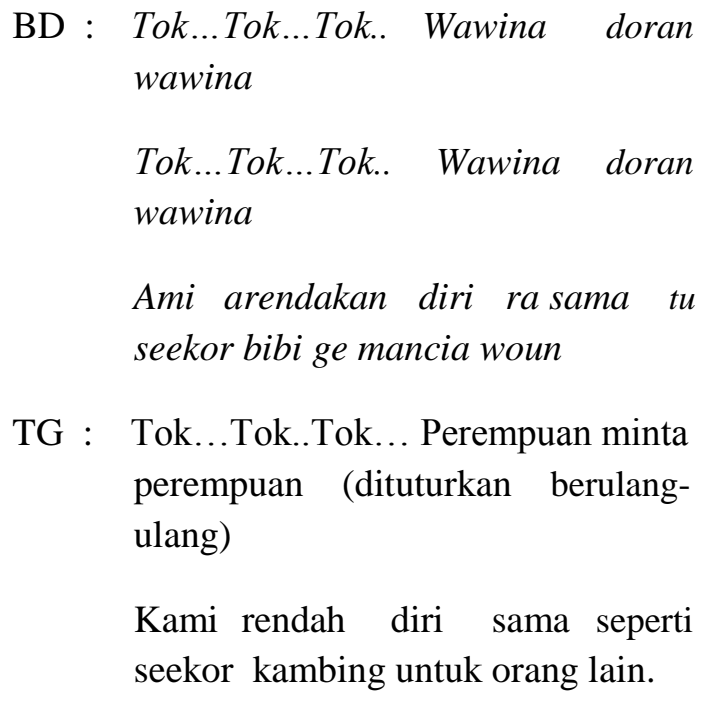




$$
\begin{aligned}
& \text { TB : } \text { Tok...Tok..Tok... Perempuan minta } \\
& \text { perempuan (dituturkan berulang- } \\
& \text { ulang) }
\end{aligned}
$$

Dari tuturan diatas terdapat nilai sosial di dalamnya, karena nilai sosial yang digambarkan dengan maksud bahwa perempuan merupakan sesuatu yang sangat berharga bagi kehidupan sang pria dan keluarganya dalam keberlangsungan hidup sehingga mereka sebagai dua keluarga yang nantinya akan menjadi satu dalam membina rumah tangga, seharusnya saling menjaga yang satu dengan yang lain, saling membina sehingga tidak terjadi kesenjangan dalam proses kehidupan yang akan dijalani. Serta menunjukan bahwa pihak mempelai laki-laki dan keluarga akan melakukan apa saja ketika diminta asalkan calon mempelai perempuan dan keluarganya bersedia menerima peminangan dari mempelai laki-laki dengan baik.

\section{Nilai Kekerabatan}

Dalam tuturan yang diucapkan pada proses upacara adat, terdapat pula nilai kekerabatan. Dapat dilihat dari tuturan meminang atau masuk minta.

$$
\begin{aligned}
& \text { BD : Matahari ma nadudu, Ami } \\
& \text { arendakan mami diri ra sama tu } \\
& \text { seekor bibi ge mancia woun } \\
& \text { TG : Matahari akan turun, kami rendah } \\
& \text { diri sama seperti seekor kambing } \\
& \text { untuk orang lain } \\
& \text { TB : Matahari akan turun, kami } \\
& \text { merendahkan diri sama seperti } \\
& \text { seekor kambing untuk orang lain }
\end{aligned}
$$


Dari tuturan untuk memberi pesan.

$$
\begin{aligned}
\text { BD : } & \text { Buah mas, tu ni daun, ge harus ta } \\
& \text { berikan ke pihak warara ni orang } \\
& \text { tua si } \\
\text { TG : } & \begin{array}{l}
\text { Buah mas dan daun harus diberikan } \\
\text { ke pihak pria dan orang tua. }
\end{array} \\
\text { TB : } & \begin{array}{l}
\text { Buah mas dan daun harus } \\
\text { diberikan kepada pihak orang tua } \\
\text { pria }
\end{array}
\end{aligned}
$$

Dapat dilihat pula dari tuturan untuk mengambil mempelai perempuan

$$
\begin{array}{ll}
\text { BD : } & \text { Hormat, beri hormat wamari } \\
& \text { keluarga warana } \\
& \text { Hormat sekaligus arendakan } \\
& \text { mami diri gepani awodi wawina } \\
& \text { sasaat ire, wawina ire mami ana } \\
& \text { ge ma awa wodi bo mami ruma ra } \\
\text { TG : } & \text { Hormat, beri hormat dari keluarga } \\
& \text { laki- laki } \\
& \text { Hormat sekaligus rendahkan kami } \\
& \text { diri sehingga membawa perempuan } \\
& \text { saat ini. } \\
& \text { Hari ini, perempuan ini kami anak } \\
& \text { dan mau di bawa ke rumah. } \\
\text { TB : } & \text { Hormat, beri hormat dari keluarga } \\
\text { laki-laki } & \\
\text { Kami memberi hormat sekaligus } \\
\text { merendahkan diri untuk mengambil } \\
\text { perempuan. }
\end{array}
$$

Anak perempuan ini akan di bawa pulang ke rumah kami. 
Dari ketiga tuturan ini terdapat pula nilai kekerabatan di dalamnya. Nilai kekerabatan dimaksud untuk mempererat rasa persaudaraan dan persekutuan dari kedua pihak keluarga, baik dalam hal memberi hormat, kejujuran, rendah diri, saling mempercayai, hal inilah yang membuat kekerabatan antara kedua keluarga ini akan berjalan dengan, tanpa ada kesalapahaman. Masyarakat Negeri Kilkoda mengakui bahwa setiap kehidupan yang dijalani tentu saja ada masalah yang jika tidak diatasi dengan baik maka akan merusak hubungan kedua keluarga, tetapi jika dengan segala baik yang dilakukan dengan rasa pengertian yang besar dari kedua keluarga maka akan terjalin kehidupan yang harmonis.

\section{KESIMPULAN}

Berdasarkan hasil penelitian seperti yang telah dipaparkan dapat disimpulkan sebagai berikut:

Masyarakat Negeri Kilkoda memandang tradisi Dahisa BabAn sebagai warisan nenek moyang yang di dalamnya terkandung nilai semangat dalam berusaha, nilai pantang menyerah, nilai rendah hati, nilai kejujuran, nilai saling mempercayai, nilai saling menghormati, nilai etika, nilai sosial, dan nilai kekerabatan.

Jenis sastra lisan dalam tradisi Dahisa BabAn di Negeri Kilkoda yaitu sastra lisan yang berupa bahasa rakyat, ungkapan tradisional dan nyanyian rakyat. Dari ketiga sastra lisan ini, yang sangat dominan digunakan dalam tradisi Dahisa BabAn yaitu bahasa rakyat. 
Nilai Budaya Dalam Tradisi Dahisa BabAn Pada Masyarakat Di Negeri Kilkoda Kecamatan Pulau Gorom Kabupaten Seram Bagian Timur

Kegiatan adat tradisi Dahisa BabAn yaitu mempererat tali silaturahim dan kegiatan ini dilakukan oleh masyarakat Negeri, dan merupakan acara adat yang masih sangat dipertahankan oleh masyarakat Pulau Gorom.

\section{E. DAFTAR PUSTAKA}

Atmazaki, 1990. Sastra dan Teori Sastra. Bandung: Sinar Baru Algensindo.

Marce M Wonata dan Danandjaya James. 2010. Nilai-nilai Budaya Dalam Sumpah Sopi (Lorke Arke) Pada Perkawinan Adat Di Desa Batumiau. Universitas Pattimura Ambon, Skripsi Tidak untuk diterbitkan.

Nyoman Kurtha Ratna, 2011. Iktisar Kesusastraan Indonesia. Yogyakarta: Pustaka Pelajar.

Semi, M. Atar. 1990. Metode Penelitian Sastra. Surabaya. Citra Wacana.

Sumardjo, Saini 1994. Memahami Kesusastraan. Bandung : Alumni

Wellek, Rene, dan Austin Werren. 1993. Teori Kesusastraan. Jakarta: Gramedia Pustaka Utama. 
Nilai Budaya Dalam Tradisi Dahisa BabAn Pada Masyarakat Di Negeri Kilkoda Kecamatan Pulau Gorom Kabupaten Seram Bagian Timur 